\title{
A Design Method for Enhancing Distribution Transformer Overload Capacity
}

\author{
Lingfeng Kou ${ }^{1, \mathrm{a}}$, Xiaolong Zhao ${ }^{1, \mathrm{~b}}$, Jinli Wang ${ }^{1, \mathrm{c}}$, Qipeng Song ${ }^{1, \mathrm{~d}}$, Zhifeng Liü ${ }^{2, \mathrm{e}}$ \\ ${ }^{1}$ Beijing Key Laboratory of Distribution Transformer Energy-Saving Technology(China Electric \\ Power Research Institute), Haidian District, Beijing 100192, China \\ ${ }^{2}$ Electric Power Research Institute of State Grid Fujian Electric Power Co., Ltd., Fuzhou 350007, \\ Fujian Province, China

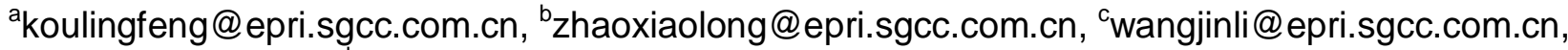 \\ dsongqipeng@epri.sgcc.com.cn, ’green1259@sina.com
}

Keywords: high overload capacity distribution transformers; heat insulation; overload capacity; test scheme

Abstract. For problems such as low rural power distribution transformer overall utilization rate, the short-time serious overload and low power supply reliability, the paper put forward a design method for enhancing distribution transformer overload capacity to solve the problem of distribution transformer overload, including material selection, temperature rise calculation and test scheme. The research direction of high overload capacity distribution transformer and problems that should be paid attention to in the application are presented with the test results.

\section{Introduction}

Transformer is one of the most important equipment in power system, especially the distribution transformer with wide distributed, large quantity, its safe and reliable operation is extremely important for the protection of power system safety, reliability and economic[1]. In China, rural power network has the characteristics of low average load rate, strong seasonal load, etc., but the problem of the short time overload is more prominent. According to statistics, the transformers throughout the year most of the time in the light load operation, mean annual load rate is low, but electricity load time is relatively concentrated, such as the Spring Festival and the busy period parts short period serious overload operation, even burned due to overload in rural power grid(Shandong, Jiangsu, Zhejiang, Hubei, Henan and other typical county power supply company statistics, short-term load rate reached more than $1.22 \%$ of the total amount of $120 \%$ ), that bring severe impact to the safety of power supply. Method dealing with the transformer overload problem mainly considers from two aspects: the one is to improve the distribution transformer overload capacity; the second is to optimize selection of transformers, select large capacity and energy saving equipment. The optimization selection of transformer has been deeply discussed and achieved great progress and achievements, a variety of new energy-saving transformer have been put into use[2,3], such as non-amorphous alloy distribution transformer, a capacity regulating distribution transformer, adaptive load distribution transformer, high overload capacity distribution transformer, according to the mode of management with primary and secondary distribution transformer.

In this paper, a comprehensive study of the distribution transformer overload operation principle and insulation materials of heat resistant grades, design scheme of high overload, puts forward technical performance index and test method, and developed a prototype.

\section{Overload operation and insulation material selection of distribution transformer}

Distribution transformer overload operation causes local overheating of the device body and leads to equipment aging or fault accidents. Improve transformer overload capacity launches mainly from two aspects, heat dissipation and heat resistance. Structure design mainly enhances distribution transformer cooling capacity, which is to optimize the structure design; insulation material selection 
is to improve the capability of heat distribution transformer, namely the insulation optimization design.

Overload operation principle of distribution transformer. Double winding of distribution transformer is set by the two windings in a closed iron core, the iron core and winding is the most basic part of the transformer, and oil tank, oil storage tank, water absorber, radiator, explosion-proof tube or pressure release valve, insulation casing. Overload operation of the transformer with a sharp rise in heating, may cause the consequence of two aspects. On the one hand, it may cause insulating oil cracking acceleration, bubbles, reducing transformer insulation strength and electrical breakdown deals damage to the transformer; on the other hand, excessive heat will reduce the mechanical strength of the winding, especially when external short circuit occurs, large electric power produced by the short-circuit current can lead to the coil axial, amplitude to deformation and damage to the transformer in a very short period of time; in addition, it may come with sealing material accelerated aging caused by oil leakage, switch contact resistance increase caused by node fever phenomenon. According to Fig. 1, the transformer windings, insulation and fuel tanks are heat direct-contacting parts, while the rest are affected by heat.

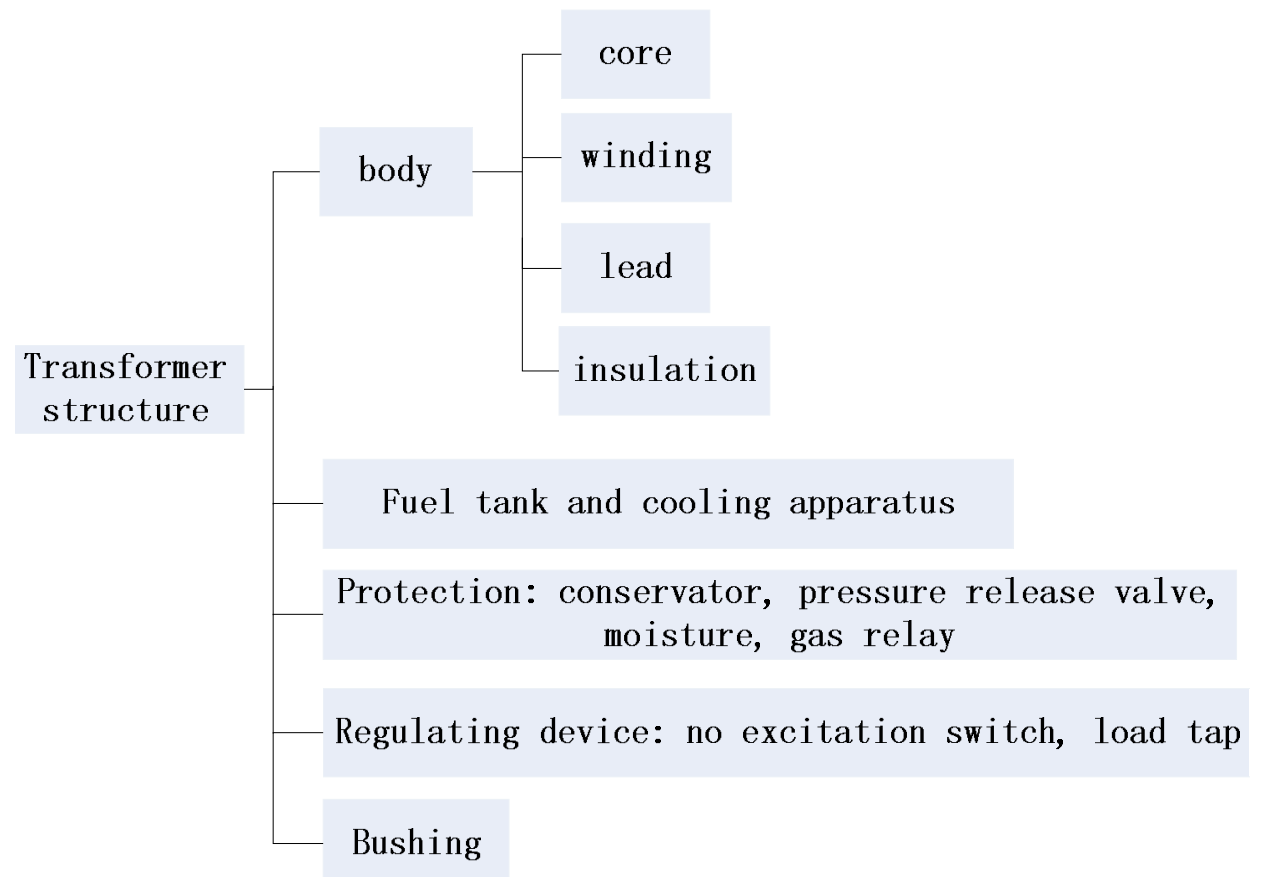

Fig.1 Transformer Structure Diagram

Therefore, the overload capacity of transformer enhances mainly from improving the distribution of heat insulation material selection, to increase the heat tolerance of distribution transformer; while winding and heat dissipating device optimization design can also effectively improve the cooling capacity of the distribution transformer.

Selection of insulating material. The insulation performance of the insulation material is closely related to the temperature. The higher the temperature is, the worse the insulation performance of the insulation material. In order to ensure the insulation strength, each kind of insulation material has an appropriate maximum allowable working temperature, in this temperature, it can be used for a long time, while rapidly aging above this temperature. According to the heat resistance, the insulation material is divided into Y, A, E, B, F, H, C and other levels, which is shown in Table 1. Oil immersed transformer require a higher insulation structure and insulation materials, electrical properties, mechanical strength, heat resistance and chemical stability, it usually uses oil paper insulation structure, composed of insulating paper (board) and transformer oil of oil paper insulation with very good electrical performance. Under short time of voltage, the compressive strength can be up to 50 $120 \mathrm{kV} / \mathrm{mm}$, and it has advantages such like rich source, simple manufacturing process and so on. 
Table 1 Classification of Insulation Materials by Heat Resistance

\begin{tabular}{|l|c|c|c|c|c|c|c|}
\hline Heat-resistant grade & Y & A & E & B & F & H & C \\
\hline Temperature Limit $\left[{ }^{\circ} \mathrm{C}\right]$ & 90 & 105 & 120 & 130 & 155 & 180 & $>180$ \\
\hline Winding temperature rise limit[K] & - & 60 & 75 & 80 & 100 & 125 & - \\
\hline
\end{tabular}

Traditional heat insulating materials level is A-class mainly[4], insulation material temperature resistance limit to $105^{\circ} \mathrm{C}$, insulating oil is mineral oil, to meet the GB2536 Standard No. 10 and No. 25 and 45 mineral transformer oil, the standard only stipulates the flash point is not less than $135^{\circ} \mathrm{C}$. Considering two functions of transformer oil: one is insulation between the transformer winding and winding, the winding and core and in oil tank; the other is heat convection, which causes iron core and winding cooling effect. At present, major domestic and foreign application of the transformer insulation oil is shown in Table 2.

Table 2 Comparison of Performance Index of Major Insulation Oils

\begin{tabular}{|l|c|c|c|c|}
\hline performance index & mineral oil & silicone oil & synthetic fat & plant oil \\
\hline Breakdown voltage $[\mathrm{kV}]$ & $30 \sim 85$ & $35 \sim 60$ & $45 \sim 70$ & $60 \sim 80$ \\
\hline Flash point $\left[{ }^{\circ} \mathrm{C}\right]$ & $100 \sim 170$ & $300 \sim 310$ & $250 \sim 300$ & $315 \sim 328$ \\
\hline Light point $\left[{ }^{\circ} \mathrm{C}\right]$ & $110 \sim 185$ & $340 \sim 350$ & $300 \sim 350$ & $350 \sim 360$ \\
\hline Condensation point $\left[{ }^{\circ} \mathrm{C}\right]$ & $-30 \sim-60$ & $-50 \sim-60$ & $-40 \sim-50$ & $-15 \sim-25$ \\
\hline $40^{\circ} \mathrm{C}$ kinematic viscosity $\left[\mathrm{mm}^{2} / \mathrm{s}\right]$ & $3 \sim 16$ & $35 \sim 40$ & $25 \sim 30$ & $16 \sim 37$ \\
\hline $100^{\circ} \mathrm{C}$ kinematic viscosity $\left[\mathrm{mm}^{2} / \mathrm{s}\right]$ & $2 \sim 2.5$ & $15 \sim 17$ & $10 \sim 15$ & $4 \sim 8$ \\
\hline
\end{tabular}

Distribution transformer insulation design mainly improve selected portion of the insulating material to improve the heat insulation ability, to ensure the overall performance and prolonging the service life of the transformer is not affected under overload operation, the performance of all other insulating material except the insulation oil in transformer must match the performance of the insulation oil, especially high heat resistance. These insulating materials include insulating paper, insulating plate, plate and etc.

\section{Scheme and cost model of high overload distribution transformer}

Except regular winding stress calculation of structure, stress and temperature rise calculation, high overload transformer design also includes winding design and insulation material selection, product technical performance indicators need to be developed. At the same time, with the minimum manufacturing cost as the design goal, optimize distribution transformer design, design idea is shown in Fig. 2.

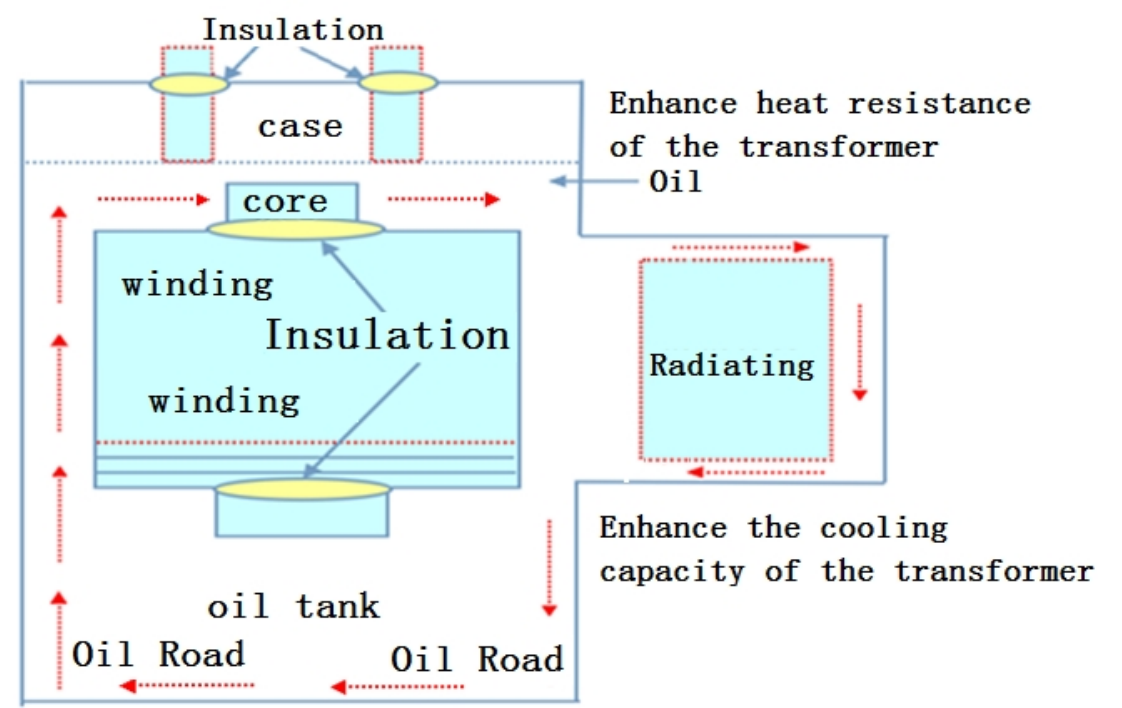

Fig.2 Design Method for Enhancing Distribution Transformer Overload Capacity 
Design scheme. By increasing the number of oil and the number of external heat sink, the method can improve the overload capacity of the distribution, while the method and the manufacturing capacity are the same, the technology is difficult. However, due to the increase in volume, the need to increase a large number of raw materials, such as steel, wire and oil, also increases. The second scheme is in the scheme based on transformer internal insulation system, to design the coil and the hot parts of device body with class F insulation materials and other parts with class B insulation materials, the scheme need comprehensive optimization calculation, with technical difficulty. The third alternative is in the scheme based on the general transformer using class $\mathrm{F}$ insulation materials and transformer oil with high flash point and ignition point, which has strong heat resistance, and the overall technical difficulty is moderate.

Selection of main insulation material. One is the selection of new hybrid transformer insulation oil, scheme uses a mixture of regular mineral oil and high burning point plant oil according to certain proportion [5], to meet the requirements in appearance, acid value, kinematic viscosity, flash point, freezing point, water soluble acids and breakdown voltage of electrical properties, and improve the insulation oil flash point and ignition at the same time. Meanwhile, the scheme can avoid the insulation oil degradation caused by conventional insulation oil, moisture absorption, moisture content, insulation performance reducing, cooling and heat dissipation reducing, and the ability of arc suppression is greatly reduced. Another is selection of high heat resistant grade of insulation paper, whose insulation performance and the mechanical strength is far more than ordinary cable paper, the dielectric coefficient and dielectric loss variation with temperature is very small, even in the state of many short circuit overlap, it will not cause mechanical damage and electrical failure nor loss of insulating materials of life due to temperature rise.

\section{Technical performance index}

Overload performance and test method. According to the characteristics of rural power network load, based on normal temperature rise test requirements, this test method meets 1.5 times the rated capacity to 6 hours (load rise and decline each 3H), 1.75 times the rated capacity to 3 hours (load rise and decline each 1.5h), 2.0 times the rated capacity with 1 hours of continuous operation, and the transformer's normal life is not affected. In addition to the same test items as the regular distribution, high overload with variable also need to carry out the overload test. After the preliminary investigation, in the premise of ensuring the full life cycle is not reduced, in the case of the application of Fig. 3, to ensure that the temperature rise in the normal range.

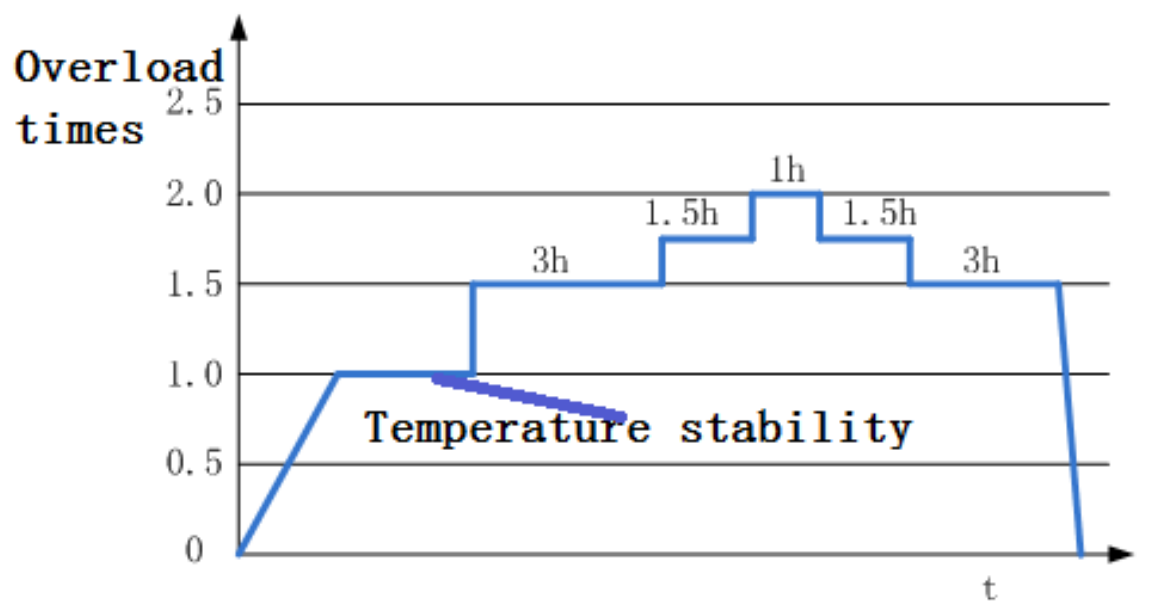

Fig.3 Overload Curve of High Overload Distribution Transformer

Basic performance parameters. The basic performance parameters of high load distribution transformer and regular distribution transformer are totally the same with the same capacity, and the basic performance parameters of SH15 type high overload with the non-crystal alloy are shown in Table 3. 
Table 3 Basic Performance Parameters of SH15 High Overload Transformer

\begin{tabular}{|c|c|c|c|c|c|c|c|c|}
\hline \multirow[b]{2}{*}{$\begin{array}{l}\text { Capacity } \\
{[\mathrm{kVA}]}\end{array}$} & \multicolumn{3}{|c|}{$\begin{array}{l}\text { Voltage combination and } \\
\text { tapping range }\end{array}$} & \multirow[b]{2}{*}{$\begin{array}{l}\text { Connection } \\
\text { group grade }\end{array}$} & \multirow{2}{*}{$\begin{array}{c}\text { No } \\
\text { load } \\
\text { loss } \\
{[\mathrm{kW}]}\end{array}$} & \multirow{2}{*}{$\begin{array}{l}\text { Load loss } \\
{[\mathrm{kW}]}\end{array}$} & \multirow{2}{*}{$\begin{array}{c}\text { No-load } \\
\text { current } \\
{[\%]}\end{array}$} & \multirow{2}{*}{$\begin{array}{c}\text { Short-circuit } \\
\text { impedance } \\
{[\%]}\end{array}$} \\
\hline & $\begin{array}{c}\text { High } \\
\text { voltage } \\
{[\mathrm{kV}]}\end{array}$ & $\begin{array}{c}\text { High } \\
\text { voltage tap } \\
\text { range[\%] }\end{array}$ & $\begin{array}{c}\text { Low } \\
\text { voltage } \\
{[\mathrm{kV}]} \\
\end{array}$ & & & & & \\
\hline 50 & \multirow{3}{*}{$\begin{array}{c}10 \\
10.5 \\
11\end{array}$} & \multirow{3}{*}{$\begin{array}{c} \pm 5 \\
\pm 2 * 2.5\end{array}$} & \multirow{3}{*}{0.4} & \multirow{3}{*}{$\begin{array}{l}\text { Dyn11/ } \\
\text { Yyn0 }\end{array}$} & 0.043 & $0.91 / 0.87$ & 1.1 & \multirow{3}{*}{4.0} \\
\hline 100 & & & & & 0.075 & $1.58 / 1.5$ & 1.0 & \\
\hline 200 & & & & & 0.12 & $2.73 / 2.6$ & 0.9 & \\
\hline
\end{tabular}

Note: The load loss values in the table above slash apply to slash Dyn11 connection group, while slash load loss values below apply Yyn0 connection group.

\section{Equipment development and testing}

Hot spot temperature calculation. Refer to GB / T 1094.7-2008 derivation method, top oil temperature rise calculation formula in load rate curve at any time is shown as Eq. 1, winding hot spot temperature rise calculation is shown as Eq. 2, average winding hot spot temperature rise calculation is shown as Eq. 3.

$$
\begin{aligned}
& \theta_{\mathrm{O}}(\mathrm{t})=\theta_{\mathrm{Oi}}+\left\{\theta_{\mathrm{Or}} \times\left[\frac{1+R \times K^{2}}{1+R}\right]^{x}-\theta_{\mathrm{Oi}}\right\} \times\left(1-e^{\frac{-t}{180}}\right) . \\
& \theta_{\mathrm{h}}(\mathrm{t})=\theta_{\mathrm{O}}(\mathrm{t})+\mathrm{H} \times \mathrm{g}_{\mathrm{r}} \times K^{1.6} . \\
& \theta_{\mathrm{r}}(\mathrm{t})=\theta_{\mathrm{h}}(\mathrm{t})-10 .
\end{aligned}
$$

In the equations, $\theta_{\mathrm{o}}(\mathrm{t})$ is top oil temperature at time $\mathrm{t}, \theta_{\mathrm{Oi}}$ is top oil temperature in the beginning, $K$ is load coefficient, $\mathrm{R}$ is loss ratio, $\mathrm{H}$ is hot spot coefficient, $\mathrm{g}_{\mathrm{r}}$ is the gradient of winding average temperature to the oil average temperature under rated current. The calculation result is shown in Table 4.

Table 4 Temperature Rise Calculation [K]

\begin{tabular}{|c|c|c|c|c|c|}
\hline condition & Top oil & HV hot & Ave.(HV) & LV hot & Ave.(LV) \\
\hline Rated & 38.2 & 50.86 & 40.86 & 50.41 & 40.41 \\
\hline 3h1.5IN & 59.39 & 83.6 & 73.6 & 82.75 & 72.75 \\
\hline $1.5 \mathrm{~h} 1.75 \mathrm{IN}$ & 71.95 & 102.93 & 92.93 & 101.84 & 91.84 \\
\hline $1 \mathrm{~h} 2.0 \mathrm{IN}$ & 83.48 & 121.84 & 111.84 & 120.49 & 110.49 \\
\hline
\end{tabular}

Test detection. In order to verify the feasibility of high overload distribution transformer design scheme, a test detection for prototype was handled, and multiple sensors were installed in the transformer to record the distribution transformer temperature rise changes, temperature rise and the overload capacity of the test current is applied in the curve of Fig. 3, result is specified in Table 5. In order to monitor the change of the load factor after the operation of the transformer, the no-load test is carried out at each load stage.

Table 5 Temperature Rise Test [K]

\begin{tabular}{|c|c|c|c|c|}
\hline condition & Top oil & Aver oil & HV Winding & LV Winding \\
\hline Rate & 38.2 & 38.5 & 40.4 & 39.2 \\
\hline 3h1.5IN & 64.9 & 59.85 & 72.3 & 69.3 \\
\hline $1.5 \mathrm{~h} 1.75 \mathrm{IN}$ & 78.3 & 72.5 & 91.3 & 86 \\
\hline $1 \mathrm{~h} 2.0 \mathrm{IN}$ & 92.2 & 84.12 & 112 & 105.4 \\
\hline
\end{tabular}

The test results show that the temperature rise data of the load operation is slightly increased, and the temperature rise of the high voltage winding and the low voltage winding exceeds the limit value. 
Taking into account that the original temperature ceiling values are for the regular A-level insulated transformer, while high overload transformer's insulation level has improved, globally reached the B level and above, meet the temperature requirements, and there a certain margin, temperature rise limit value corresponding to each insulation level is shown in Table 6[6]. In addition, the no-load loss after the operation of the transformer is not changed, which is in line with the standard requirements.

Table 6 Temperature Rise Limit [K]

\begin{tabular}{|c|c|c|c|}
\hline name & Rate A & Rate B & Rate F \\
\hline Top oil & 55 & 80 & 100 \\
\hline Winding(average) & 65 & 85 & 100 \\
\hline Winding(hot) & 65 & 95 & 110 \\
\hline Core, oil tank and surface & 55 & 80 & 100 \\
\hline
\end{tabular}

Compared with the regular transformer A-class insulation value of temperature rise, high overload distribution transformer's temperature ceiling value is greatly improved. It is proved that high overload transformer optimization space still exists, but also increases the pressure of the equipment development, transformer insulation oil temperature rise will lead to transformer mailbox thermal expansion pressure increasing, also increase the requirements for transformer insulating oil.

\section{Conclusions}

This paper analyzes the promotion with overload capacity of the technology principle, put forward the design scheme of high overload distribution transformer, and the prototype was tested to verify the feasibility of high overload distribution transformer design scheme and technology. High overload distribution transformer development still needs some further research: (1) high overload with variable compared with the traditional variable investment has increased, if the test scheme is reduced slightly, how can the investment effectively reduce, to offer practical basis for overload ability promotion of the regular transformers; (2) at present, mixed insulating oil technology is still in the test stage, mature products has not formed yet, cost and maintenance costs need to be further studied; (3) high overload with the change of life has not been proven, which needs further study.

\section{Acknowledgements}

This work was financially supported by State Grid Science and Technology Project (PDB17201400055).

\section{References}

[1] Liu Xingping, Distribution Transformers Health Condition Monitoring and Evaluation Methods, Chongqing, 2013. (In Chinese)

[2] K. Karsi, D. Kerenyi \& L. Kiss, Large Power Transformer, Elsevier, 1987.

[3] H. J. Kirch, Transformer insulation engineering, WICON Insulation Conference, Rapperswil, Switzerland, September 1996.

[4] Jiang Guozhu, Zhao Yuzhen, Xie Yu, High Performance Ignition Transformer Oil and Use, synthetic lubricating materials, 2010, 37 (2): 33-36. (In Chinese)

[5] PROCEEDINGS, Liang Shuai Wei, Li Jian, Yin Jianguo, Hao Jian, Chinese CSEE, 2009, 29 (13): 117 -123. (In Chinese)

[6] State Grid, Q-GDW 11190-2014 High Overload Capacity of Rural Power Distribution Transformers Technical Guideline, China Electric Power Press, Beijing, 2014. 